\title{
EDITORIAL
}

\section{Revitalizing Paradigms: Exemplars in Legal Research and Education}

\author{
Carel Smith
}

It seems to have been the paradigm of legal theory of the twentieth century: the study of law from the perspective of the judge's office. In the first half of the century, legal theorists such as Gény, Holmes, and Scholten criticized the dominant formalistic accounts of law by thoroughly analyzing the legal reasoning processes. In this respect, the judge's office has been considered to be exemplary for legal scholarship as such, for it is in the figure of the judge that all constitutive elements of the legal system come together: authority and process, rule, facts and decision.

This paradigm proved to be a fruitful one, as the judiciary remained the focal point of legal analysis for the next generation of legal scholars. MacCormick, Dworkin and Robert Alexy, to mention some of the most influential theorists, all take the perspective of the judge as the proper starting point for the construction of a theory of law. The judge's perspective is considered to be exemplary for the legal scholar, albeit we still need scholars to reveal all characteristics of the legal mind as exemplified by the judge (compare Dworkin's Hercules and Posner's How Judges Think).

In this respect, Maarten van Wel's contribution to this second issue of Law and Method is most opportune, as he describes the raio-training - the training that Law School graduates undergo in order to become a judge - from an internal point of view. One might expect that an important part of the training consists in expounding the legal methodology or standards of legal adjudication that are characteristic for the judiciary. Interestingly, Van Wel's account reveals that becoming a judge is not so much a matter of mastering a technique. Rather, it is a process of being initiated and disciplined in a culture. During the training, it is not a set of methodological rules - and instructions when and how to apply them - that are central, but the practices of senior judges. The judges serve as role model, that is, as exemplar, for the novices. The training has been completed successfully only after the novice has internalized the behavioral norms of the seniors, first through copying, then by internalizing the behavior of the judges.

Van Wel's account supports a recent claim, made in the wake of Kuhn's notion of the role of paradigms in science: the claim that scientific research is driven by perceived similarity to an exemplar, rather than by following rules. According to this method, it is not a set of methodological rules - and instructions when and how to apply them - that are central, but the practices of legal practitioners. According to Thomas Nickles (2000), the most interesting methodological feature of Kuhn's The Structure of Scientific Revolutions (1996) is his account of problem-recognition 
and puzzle solving as exemplar-based rather than explicitly rule-based. And Alexander Bird (2005, p. 101) holds that the core idea of the paradigm is not the paradigm as 'disciplinary matrix', but the paradigm as exemplar. Kuhn describes the paradigm as an accepted example of actual scientific practice, which provides a model from which spring particular coherent traditions of scientific research. But the coherence displayed by the research tradition, says Kuhn (1996, p. 17), may not imply even the existence of a full set of rules that additional historical or philosophical investigation might uncover.

Kuhn developed these ideas in the early sixties, but later shied away from his untimely account of the methodology of scientific research - untimely, because at that time the prevalent ideas in philosophy and science considered the underlying structure of reasoning as a matter of following rules. Kuhn was, therefore, not able to support his claim empirically (Nickles 2000; Bird 2005). Recent developments in artificial intelligence and psycho-linguistics, however, support the importance of pattern-recognition, analogical reasoning and case-bound-reasoning in thinking. ${ }^{1}$ Since these forms of reasoning are learned through practice with exemplars, Kuhn's claim that scientific research is lead by exemplars seems worthwhile to be reassessed.

For legal methodology, the importance of exemplary reasoning might serve as a fresh starting point to reevaluate the role of rules and deductive logic, which some scholars consider to be prerequisite in the production of genuine legal knowledge. ${ }^{2}$ The role of exemplars in legal reasoning and theory might also shed light on the alleged distinction between 'fact' and 'value'. If scientific research is lead by exemplars rather than by subject-independent facts, then the truth of scientific theories is based, at least in part, upon values - for the acceptance of an exemplar is an act of faith to some extent, guided by the expectation of the fruitfulness of the theory or the acceptance of the authority of the teacher. ${ }^{3}$

The upshot of these introductory remarks is that the concept of 'method' is much broader than the set of explicit methodological rules by which our theories are formally justified and accepted. Part of the legal methodology are non-algorithmic practices, like pattern-recognition and the comparison of similarities and differences, as well as processes of imitation and initiation. The noun 'method' in this journal's title thus comprises both the methodological practices of the scientific community and the processes that are prevalent in teaching. This seems most appropriate for a journal that aims to reflect on legal science as well as education in law.

1 Margolis (1987) proposes pattern-recognition as the basis of all cognition. For case-bound-reasoning see Leake 1998 and Dunbar 1996.

$2 \quad$ Notably Schauer 1995, Alexander 1996, p. 72; Posner 2006.

3 Kuhn 1996, p. 23. For the role of tradition and teachers, see Gadamer 1989, especially p. 277-285. 


\section{References}

Alexander 1996

L. Alexander, 'Bad Beginnings', University of Pennsylvania Law Review 1996-1.

\section{Bird 2005}

A. Bird, 'Naturalizing Kuhn', Proceedings of the Aristotelian Society 2005-1, p. 99-117.

Dunbar 1996

K. Dunbar, 'How Scientists Really Reason', in: R. Sternberg \& J. Davidson, The Nature of Insight, Cambridge MA: MIT Press 1996, p. 365-395.

\section{Gadamer 1989}

H.-G. Gadamer, Truth and Method, New York: Continuum 1989.

\section{Kuhn 1996}

T. Kuhn, The Structure of Scientific Revolutions, Chicago: The University of Chicago Press 1996 [1962].

\section{Leake 1998}

D. Leake, 'Case-Based Reasoning', in: W. Bechtel \& G. Graham, A Companion to Cognitive Science, Oxford: Blackwell 1998, p. 465-476.

\section{Margolis 1987}

H. Margolis, Patterns, Thinking, and Cognition. A Theory of Judgment, Chicago: University of Chicago Press 1987.

\section{Nickles 2000}

T. Nickles, 'Kuhnian Puzzle Solving and Schema Theory', Philosophy of Science 2000, p. S242-S255.

\section{Posner 2006}

R.A. Posner, 'Reasoning by Analogy', Cornell Law Review 2006-3, p. 761-774.

\section{Schauer 1995}

F. Schauer, Playing by the Rules. A Philosophical Examination of Rule-Based DecisionMaking in Law and in Life, Oxford: Oxford University Press 1995. 